UDC 332.1

LBC 65.9(2)32

\title{
PUBLIC-PRIVATE PARTNERSHIPAS A FORM OF DEVELOPMENT OF THE AGRO-INDUSTRIAL COMPLEX OF THE RUSSIAN FEDERATION
}

\author{
Albert G. Mnatsakanyan \\ Kaliningrad State Technical University, Kaliningrad, Russian Federation \\ Viktor A. Maliy \\ Kaliningrad State Technical University, Kaliningrad, Russian Federation
}

\begin{abstract}
The article examines the current state of public-private partnership in the agro-industrial complex of the Russian Federation, provides a refined definition of public-private partnership. The authors give a full determination of the public-private partnership in Russia. The structure of existing agro-industrial clusters on the territory of the Russian Federation is studied. The article contains characteristics of the agro-industrial complex, which affect the low involvement of private investment. The state of the agro-industrial complex is analyzed, the main problems of applying public-private partnerships in the agro-industrial complex are revealed, and recommendations for improving the mechanism for applying public-private partnerships are given. The study highlights the main advantages of using the mechanism of public-private partnership, analyzes trends and prospects for using this mechanism. The scientific works of domestic and foreign scientists in the field of public-private partnership and agro-industrial complex became the methodological basis of scientific research. System analysis, a set of methods of economic and statistical analysis, methods of synthesis and analysis of economic information, a comparative method were used as the methods of research. The article concludes that it is necessary to use the mechanisms of public-private partnership in the agro-industrial complex of the Russian Federation regarding the need for significant investments in the industry to maintain competitiveness. It is necessary to use such forms of public-private partnership that will use financial and administrative resources of state authorities even at the initial stage of the project, and later private business will repay the share of the invested state funds, up to the privatization of the property complex. This form of cooperation will help reduce the risks of private investors and attract new investments in the agro-industrial complex of the Russian Federation. Besides, the conducted research allows to draw a conclusion that this form of public-private partnership can be realized with the help of agro-industrial clusters.
\end{abstract}

Key words: public-private partnership, agro-industrial complex of the Russian Federation, agro-industrial clusters, state support, centers for cluster development.

УДК 332.1

ББК $65.9(2) 32$

\section{Фें ГОСУДАРСТВЕННО-ЧАСТНОЕ ПАРТНЕРСТВО КАК ФОРМА РАЗВИТИЯ АГРОПРОМЫШЛЕННОГО КОМПЛЕКСА РОССИЙСКОЙ ФЕДЕРАЦИИ}

\author{
Альберт Гургенович Мнацаканян
}

Калининградский государственный технический университет, г. Калининград, Российская Федерация

Виктор Андреевич Малий

Калининградский государственный технический университет, г. Калининград, Российская Федерация

Аннотация. В статье рассматривается современное состояние государственно-частного партнерства в агропромышленном комплексе Российской Федерации, дается уточненное определение государственно-частного партнерства. Приводится пример применения государственно-частного партнерства в России. Рассмат- 
ривается структура агропромышленных кластеров, существующих на территории Российской Федерации. Изучаются особенности агропромышленного комплекса, влияющие на низкую вовлеченность частных инвестиций. Анализируется состояние агропромышленного комплекса, выявляются основные проблемы применения государственно-частного партнерства в агропромышленном комплексе, даются рекомендации по совершенствованию механизма применения государственно-частного партнерства. В ходе исследования выделяются основные преимущества использования механизма государственно-частного партнерства, анализируются тенденции и перспективы использования данного механизма. Методологической основой научного исследования стали научные труды отечественных и зарубежных ученых в области государственно-частного партнерства и агропромышленного комплекса. В качестве методов исследования применялись общие и частные методы, включая системный анализ исследуемых явлений, совокупность методов экономико-статистического анализа, методы синтеза и анализа экономической информации, сравнительный метод.

В статье делается вывод о необходимости использования механизмов государственно-частного партнерства в агропромышленном комплексе Российской Федерации в связи с необходимостью значительных инвестиций в отрасль для поддержания конкурентоспособности. Необходимо использовать такие формы государственно-частного партнерства, которые будут использовать финансовые возможности и административный ресурс государственных органов власти еще на начальном этапе проекта, а впоследствии частный бизнес будет погашать долю вложенных государственных средств, вплоть до приватизации имущественного комплекса. Данная форма взаимодействия поможет снизить риски частных инвесторов и привлечь новые инвестиции в агропромышленный комплекс Российской Федерации. Кроме того, проведенное исследование позволяет сделать вывод о том, что данная форма государственно-частного партнерства может быть реализована при помощи агропромышленных кластеров.

Ключевые слова: государственно-частное партнерство, агропромышленный комплекс Российской Федерации, агропромышленные кластеры, государственная поддержка, центры кластерного развития.

Важной частью экономической политики является развитие агропромышленного комплекса, который непосредственно влияет на уровень народного благосостояния, поскольку продукция АПК составляет более $60 \%$ товаров торговли. Главной государственной задачей выступает организация и стимулирование инновационной деятельности в аграрном секторе экономики. Очевидно, что из-за комплексного характера многих проблем отечественного АПК, а также из-за введения странами Европейского союза экономических санкций против России отдельные его отрасли и хозяйствующие субъекты не в состоянии обеспечить решение подобной задачи за счет собственных средств.

При реализации мер поддержки отечественного агропромышленного комплекса необходимо учитывать опыт передовых в аграрном отношении стран. Оптимальным решением может стать активное взаимодействие государственного и частного капиталов на принципах государственно-частного партнерства. Государственное регулирование, взаимодействие государства и бизнес-сообщества в сельском хозяйстве разных стран отличается большим разнообразием использования экономических и финансовых механизмов и инструментов, различаются степень и формы государственного вмешательства в частный бизнес. Таким образом, изучение, детальная проработка и внедрение ГЧП в сферу сельского хозяйства являются весьма актуальными в современных условиях функционирования российской экономики. Целью данной работы является изучение современного состояния государственно-частного партнерства в АПК, а также разработка рекомендаций по его внедрению в отечественную практику.

В настоящее время существует множество различных определений понятия государственно-частное партнерство. В общем понимании это система эффективного взаимодействия государства и бизнеса, использующая инвестиционные ресурсы предпринимателей как возможность для развития экономики страны, достижения важных общественных целей публичного управления [5]. С помощью ГЧП реализуются различные общественно значимые проекты, начиная от развития отдельных отраслей экономики и заканчивая крупными проектами по предоставлению общественных услуг. Особенностью такой формы взаимодействия является то, что первоначальные активы сохраняются в собственности государства. Частные партнеры привносят в проект свой капитал, инновационные технологии и опыт предпринимательской деятельности, а госу- 
дарство использует свои бюджетные и административные ресурсы. Механизмы взаимодействия государства и бизнес-сообщества в ряде стран активно применяются на протяжении долгого времени, успешно функционируют и постоянно совершенствуются. К ним можно отнести такие страны, как Великобритания, Франция, Германия.

В России пока имеется небольшой опыт применения государственно-частного партнерства. Кроме того, следует отметить, что сельское хозяйство нашей страны в настоящее время находится на стадии интенсивных преобразований и развития. По экспертным оценкам, инвестиционный потенциал АПК до 2020 г. составит свыше 4 трлн руб. [5]. Причем значительная часть этих инвестиций должна быть профинансирована за счет внешних источников. Наиболее целесообразным решением проблемы привлечения средств для развития АПК является организация ГЧП между органами власти, фермерами и сельскохозяйственными организациями. Однако в настоящее время проектам государственно-частного партнерства в области сельского хозяйства не уделяется достаточного внимания. Возможность осуществления данного типа проектов лишь недавно была включена в Федеральный закон о государственно-частном партнерстве.

Вместе с тем в отечественном АПК сложились все необходимые предпосылки для использования механизмов ГЧП. Значительная доля продовольственного рынка закреплена за сельхозтоваропроизводителями и переработчиками, объединившимися в Ассоциацию российских производителей крахмалопаточной продукции «Роскрахмалпатока» (95\%), Российский союз производителей соков (92 \%), Союз производителей пищевых ингредиентов (90\%), Российский союз пекарей $(80 \%)$, Российский птицеводческий союз «Росптицесоюз» (80\%), Ассоциацию «Теплицы России» (75 \%), Масложировой союз России (72\%), Союз сахаропроизводителей России «Союзроссахар» (70 \%), Ассоциацию «Пивоиндустрия〉 (70 \%). Всего на территории России, по данным Минсельхоза, функционируют 93 отраслевых союза и ассоциации АПК, взаимодействующих с профильным министерством и другими ведомствами [7].
Таким образом, в России в сфере АПК, так же как и в других зарубежных странах, успешно функционируют различные ассоциации сельскохозяйственных товаропроизводителей и переработчиков продукции АПК. Кроме того, на территории Российской Федерации существуют аграрные кластеры - добровольные и неформальные объединения усилий сельскохозяйственных товаропроизводителей (различных форм хозяйствования), переработчиков продукции конкретного региона с целью производства, переработки и реализации сельскохозяйственной продукции, защиты окружающей среды. Аграрные кластеры являются выгодной формой объединения как для самих производителей сельхозпродукции, так и для сервисных, перерабатывающих, торговых предприятий, включая заводы по производству сельскохозяйственной техники. Главной особенностью кластеров является обязательное требование к сохранению конкуренции: каждый товаропроизводитель, входящий в кластер, является самостоятельным игроком на рынке, осуществляя свою деятельность в рамках выбранной организационно-правовой формы. Активное взаимодействие с внешней средой является новшеством при вступлении в кластер, ведь только при использовании эффекта синергии возможно достичь общих целей кластера. Данный факт является значимым для производителей сельскохозяйственной продукции, так как многие из проблем, связанных с организационными, производственными и управленческими вопросами, не могут быть решены товаропроизводителями самостоятельно. Поддерживая кластерную политику, государство создает возможности для инновационного развития субъектов малого и среднего предпринимательства, улучшает функционирование механизмов перераспределения доходов, а также обеспечивает заинтересованность всех участников кластера в конечных результатах деятельности, тем самым стимулируя совместную деятельность.

По данным Министерства сельского хозяйства Российской Федерации, с 2010 года на территории страны поддерживается создание центров кластерного развития, что уже привело к созданию более десятка агропромышленных кластеров (см. рисунок) [1]. 


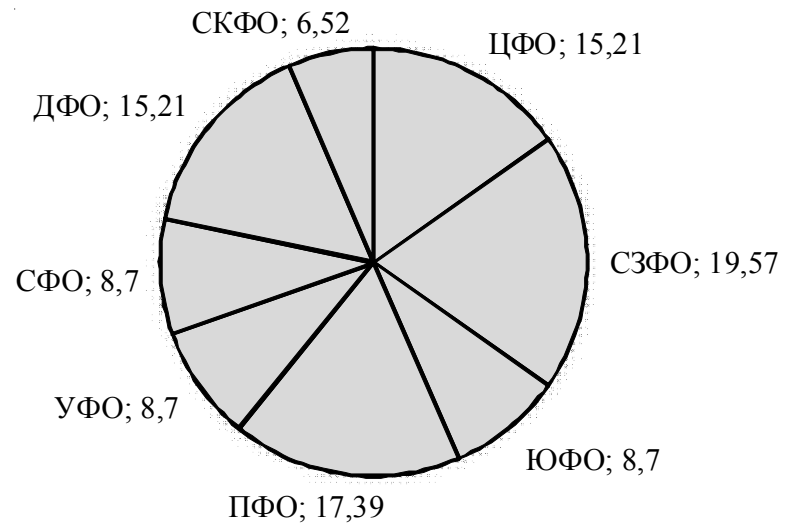

Рисунок. Структура агропромышленных кластеров по федеральным округам Российской Федерации в 2016 г., \%

Примечание. Составлено по: [1].

Однако проблема модернизации сельского хозяйства не может быть полностью решена только за счет использования данного вида партнерства. Главной проблемой, препятствующей модернизации отечественного АПК, является высокий риск многих видов сельскохозяйственного производства, поскольку значительная часть территории России относится к зоне рискованного земледелия. Это приводит к разорению сельхозпроизводителей и сокращению их числа. Согласно данным Федеральной службы государственной статистики, за период с 1 июня 2006 г. по 1 марта 2016 г. количество фермерских хозяйств сократилось с 285,1 тыс. до 219,5 тыс. [2]. Данный факт говорит о том, что на современном этапе развития агропромышленному комплексу требуется государственная поддержка. С целью обеспечения стабильного и эффективного развития АПК государству необходимо разделить риски производителей сельскохозяйственной продукции, способствовать модернизации отрасли, привлечению дополнительных инвестиций.

Одним из способов решения обозначенных задач являются различные формы сотрудничества бизнеса и государства в АПК. Кроме того, существование агропромышленных кластеров сделало возможным продвижение ГЧП на более высокий организационный уровень, прежде всего, за счет усиления эффекта синергии благодаря организационно-финансовой государственной поддержке.

Поскольку аграрная сфера во многом страдает от значительного недофинансирова- ния научных исследований и влияния внешних факторов, использование механизма ГЧП позволяет снизить риск для отдельных частных партнеров и одновременно способствовать адаптации и распространению новых результатов исследований или имеющихся знаний и технологий.

Одним из инструментов ГЧП на сегодняшний день является программно-целевой подход, реализуемый через Государственную программу развития сельского хозяйства и регулирования рынков сельскохозяйственной продукции, сырья и продовольствия, действовавшую в 2008-2012 гг. и пролонгированную на 2013-2020 гг. [5]. Государство выполняет организационно-экономическую функцию развития АПК, организует и координирует разработку целевых государственных, ведомственных и региональных программ и инновационных инвестиционных проектов, обеспечивает формирование инновационной инфраструктуры, не выполняя при этом функции агробизнеса. В отечественной практике реализация крупных ГЧП-проектов осуществляется преимущественно в виде использования средств Инвестиционного фонда РФ и других источников финансирования крупных инвестиционных проектов, соответствующих основным направлениям стратегического развития РФ. Однако из всей совокупности инвестиционных проектов, реализуемых на условиях ГЧП в России, только 8 относятся к сфере АПК, из которых 4 реализуются в Тамбовской области, 2 - в Республике Мордовия, по одному - в Брянской области и Алтайском 
крае [5]. В ближайшее время планируется запуск еще нескольких пилотных проектов в формате ГЧП в сельском хозяйстве.

Многоаспектное изучение проблем и перспектив развития государственно-частного партнерства и снижения рисков при реализации инвестиционных проектов в АПК регионов позволяет сделать вывод, что на современном этапе актуальной является оптимизация форм и моделей ГЧП. Из всего многообразия форм ГЧП следует отобрать такие, которые будут опираться на финансовые возможности и административный ресурс государственных органов власти еще на начальном этапе проекта. Впоследствии, когда акционерный или частный бизнес в этом проекте будет получать прибыль, он будет погашать государственную долю вложенного капитала вплоть до приватизации всего имущественного комплекса. Важным на современном этапе является также инновационное и технологическое совершенствование системы устойчивого продовольственного обеспечения, что подразумевает придание инновационности организационной структуре отечественного АПК, обеспечивающей наиболее оптимальное решение проблем отрасли.

Анализ существующих способов государственной поддержки АПК в Российской Федерации позволяет выделить основные меры финансовой поддержки, к которым относятся: гранты из федерального бюджета, возмещение части затрат на уплату страховых премий, кредитов и займов, предоставление предприятиям АПК кредитов на льготных условиях.

Анализ проектов агропромышленного комплекса, использующих ГЧП (см. таблицу), позволяет сделать вывод о том, что за последние 10 лет проекты ГЧП в данной отрасли в первую очередь направлены на новое строительство, что требует больших капитальных затрат и длительного срока ввода в эксплуатацию, в то время как по реконструкции и техническому перевооружению, а также воспроизводству основных фондов не было ни одного проекта [7].

В первую очередь это связано со спецификой отрасли, имеющей высокий уровень риска. Но поскольку одной из целей государственно-частного партнерства является ми- нимизация рисков, проекты, направленные на воспроизводство основных фондов, пока являются менее привлекательными. В связи с этим оптимальной формой государственночастного партнерства, учитывающей специфику агропромышленной отрасли, могут стать проекты на основе агропромышленных кластеров. Данная форма взаимодействия предполагает использование контрактов жизненного цикла, а также инструментов по воспроизводству основных фондов. Кроме того, в рамках таких проектов могут быть использованы формы взаимодействия, применяемые в других отраслях экономики, например концессии, разные типы контрактов, соглашения о разделе продукции.

Однако бизнесу в первую очередь интересны проекты, которые могут обеспечить постоянный и высокий доход, в то время как АПК является малорентабельной отраслью с большим количеством рисков. Кроме существования политических, макроэкономических, юридических и других проектных рисков, существуют также специфические риски, возникающие исключительно в проектах данной отрасли. К ним относят территориальные (суровые условия Крайнего Севера), природно-климатические, биологические (риск инфекций, иных природных явлений), эколого-техногенные риски (загрязнение окружающей среды) [4]. Следовательно, для того чтобы максимально привлечь финансовые ресурсы в АПК, а также с целью развития инновационной системы, необходимо разрабатывать и внедрять такие агропромышленные формирования кластерного типа, в которых риск инвесторов сводился бы к минимуму, например в форме инновационных кластеров. Их формирование зависит от следующих факторов: благоприятных почвенноклиматических условий для производства сельскохозяйственной продукции и продовольствия; наличия трудовых и земельных ресурсов для производства сельхозпродукции; опережающих сроков начала использования результатов научной и научно-технической деятельности, научной организации-участника инновационного кластера по производству определенной сельскохозяйственной продукции; использования собственных внешнеэкономических и экспортных связей, а также финансовых средств для приобретения новых технологий и обору- 
Проекты агропромышленного комплекса, использующие государственно-частное партнерство

\begin{tabular}{|c|c|c|c|c|}
\hline Регион & Название проекта ГЧП & $\begin{array}{c}\text { Уровень } \\
\text { реализации } \\
\text { проекта } \\
\end{array}$ & $\begin{array}{c}\text { Объем } \\
\text { инвестиций, } \\
\text { млн руб. } \\
\end{array}$ & $\begin{array}{c}\text { Удельный вес по } \\
\text { участию в проекте, \% }\end{array}$ \\
\hline $\begin{array}{l}\text { Республика Мордовия } \\
\text { (ПФО) }\end{array}$ & $\begin{array}{l}\text { Строительство комбикормового за- } \\
\text { вода в Рузаевском районе Респуб- } \\
\text { лики Мордовия }\end{array}$ & Региональный & 583,4 & $\begin{array}{l}9 \%-\text { государство } \\
91 \%-\text { бизнес }\end{array}$ \\
\hline \multirow[t]{4}{*}{$\begin{array}{l}\text { Тамбовская область } \\
\text { (ЦФО) }\end{array}$} & $\begin{array}{l}\text { Первая очередь программы разви- } \\
\text { тия АПК Тамбовской области }\end{array}$ & Региональный & 13554,4 & $\begin{array}{l}8 \%-\text { государство } \\
92 \%-\text { бизнес }\end{array}$ \\
\hline & $\begin{array}{l}\text { Вторая очередь программы разви- } \\
\text { тия АПК Тамбовской области }\end{array}$ & Региональный & 5910,7 & $\begin{array}{l}13 \% \text { - государство } \\
87 \% \text { - бизнес }\end{array}$ \\
\hline & $\begin{array}{l}\text { Строительство комплекса по } \\
\text { производству } 30 \text { тыс. т мяса } \\
\text { свинины в живом весе в год с ком- } \\
\text { бикормовым заводом мощностью } \\
120 \text { тыс. т комбикорма в год на } \\
\text { территории Моршанского района } \\
\text { Тамбовской области } \\
\end{array}$ & Региональный & 3982,45 & $\begin{array}{l}26 \% \text { - государство } \\
74 \% \text { - бизнес }\end{array}$ \\
\hline & $\begin{array}{l}\text { Строительство комплекса по } \\
\text { производству } 90 \text { тыс. т мяса } \\
\text { свинины в живом весе в год с } \\
\text { убойным производством мощ- } \\
\text { ностью } 1573 \text { тыс. голов в год и } \\
\text { комбикормовым заводом мощ- } \\
\text { ностью } 290 \text { тыс. т комбикорма в год }\end{array}$ & Региональный & 16801,8 & $\begin{array}{l}12 \% \text { - государство } \\
88 \% \text { - бизнес }\end{array}$ \\
\hline $\begin{array}{l}\text { Владимировская } \\
\text { область (ЦФО) }\end{array}$ & $\begin{array}{l}\text { Создание агропромышленного пар- } \\
\text { ка «Ставровский» в п. Ставрово }\end{array}$ & Муниципальный & 2201,6 & $\begin{array}{l}\text { Нет деления по до- } \\
\text { лям }\end{array}$ \\
\hline $\begin{array}{l}\text { Омская область } \\
\text { (СФО) }\end{array}$ & $\begin{array}{l}\text { Целевая программа развития АПК } \\
\text { в Омской области }\end{array}$ & Региональный & 76468,6 & $\begin{array}{l}15 \% \text { - государство } \\
85 \%-\text { бизнес }\end{array}$ \\
\hline \multirow[t]{5}{*}{$\begin{array}{l}\text { Алтайский край } \\
\text { (СФО) }\end{array}$} & $\begin{array}{l}\text { Строительство свинокомплекса } \\
\text { производительностью } 32,5 \text { тыс. т } \\
\text { мяса в живом весе в год }\end{array}$ & Региональный & 4711,1 & $\begin{array}{l}\text { Нет деления по до- } \\
\text { лям }\end{array}$ \\
\hline & $\begin{array}{l}\text { Создание вертикально интегриро- } \\
\text { ванного птицеводческого комплек- } \\
\text { са с незамкнутым циклом по } \\
\text { производству } 63 \text { тыс. т мяса } \\
\text { бройлеров в год }\end{array}$ & Региональный & 6900,2 & $\begin{array}{l}\text { Нет деления по до- } \\
\text { лям }\end{array}$ \\
\hline & $\begin{array}{l}\text { Строительство и техническое ос- } \\
\text { нащение свиноводческого комп- } \\
\text { лекса на } 300 \text { тыс. голов в год }\end{array}$ & Региональный & 6700,0 & $\begin{array}{l}\text { Нет деления по до- } \\
\text { лям }\end{array}$ \\
\hline & $\begin{array}{l}\text { Строительство животноводческого } \\
\text { комплекса по производству молока } \\
\text { и мяса }\end{array}$ & Региональный & 5418,0 & $\begin{array}{l}\text { Нет деления по до- } \\
\text { лям }\end{array}$ \\
\hline & $\begin{array}{l}\text { Создание свиноводческого комп- } \\
\text { лекса в Тальменском районе Ал- } \\
\text { тайского края (1 этап) }\end{array}$ & Региональный & 2508,67 & $\begin{array}{l}23 \% \text { - государство } \\
77 \% \text { - бизнес }\end{array}$ \\
\hline $\begin{array}{l}\text { Брянская область } \\
\text { (ЦФО) }\end{array}$ & $\begin{array}{l}\text { Строительство завода по произ- } \\
\text { водству замороженного приготов- } \\
\text { ленного картофеля и картофель- } \\
\text { ных хлопьев }\end{array}$ & Региональный & 4856,4 & $\begin{array}{l}5 \% \text { - государство } \\
95 \% \text { - бизнес }\end{array}$ \\
\hline
\end{tabular}

Примечание. Составлено по: [1].

дования собственных торговых марок и брендов. Применение наработанного зарубежного опыта позволит использовать все имеющиеся ресурсы бизнеса и власти для достижения необходимого развития отраслей национальной экономики.
Эффективным инструментом формирования инновационной системы АПК и развития государственно-частного партнерства в ближайшее время должны стать технологические платформы как наиболее современная форма ГЧП, направленная на согласование приорите- 
тов научно-технической политики развития сельского хозяйства и перерабатывающих отраслей между бизнесом, наукой и образованием в целях повышения конкурентоспособности АПК в целом и отдельных территорий, комплексов и организаций в частности.

Таким образом, применение организационных механизмов ГЧП является отправной точкой для развития нового уровня отношений между государством и бизнесом в сфере агропромышленного комплекса, позволяющих использовать сильные стороны государственных и частных партнеров для достижения роста эффективности, мобилизации ресурсов и инвестиций при решении приоритетных задач, реализации инновационных проектов, снижении рисков.

\section{СПИСОК ЛИТЕРАТУРЫ}

1. ВШЭ подготовила прогноз развития агропромышленно комплекса до 2030 года // Официальный сайт Национального исследовательского университета «Высшая школа экономики». - Электрон. текстовые дан. - Режим доступа: https:// www.hse.ru/news/expertise/201397875.html. - Загл. с экрана.

2. Гладкова, Е. П. Анализ различных форм партнерства в сфере АПК: проблемы и перспективы / Е. П. Гладкова // Управление экономическими системами : электрон. науч. журн. - Электрон. текстовые дан. - Режим доступа: http://uecs.ru/uecs-9082016/item/4041-2016-08-09-06-27-55. - Загл. с экрана.

3. Кочеткова, С. А. Механизмы ГЧП в российском АПК / С. А. Кочеткова // Фундаментальные исследования : науч. журн. - Электрон. текстовые дан. Режим доступа: https://www.fundamental-research.ru/ ru/article/view?id=40867. - Загл. с экрана.

4. Особенности взаимодействия государственных и негосударственных финансов в проектах государственно-частного партнерства на региональном уровне / А. Г. Мнацаканян, В. В. Генне // Известия КГТУ. - 2011. - № 22. - С. 18-23.

5. Мнацаканян, Р. А. Становление и развитие государственно-частного партнерства / Р. А. Мнацаканян // Балтийский экономический журнал. 2015. - № 2 (14). - C. 91-98.

6. Отраслевые союзы Российской Федерации // Официальный сайт Министерства сельского хозяйства Российской Федерации. - Электрон. текстовые дан. - Режим доступа: http://mcx.ru/ministry/ industry-unions/. - Загл. с экрана.

7. Харин, А. Г. Природопользование и экология с основами экономики : учеб. пособие / А. Г. Ха- рин, Г. С. Харин. - Калининград : Балт. ин-т экономики и финансов, 2006. -130 с.

8. Число фермерских хозяйств // Официальный сайт Федеральной службы государственной статистики. - Электрон. текстовые дан. - Режим доступа: http://www.gks.ru/. - Загл. с экрана.

\section{REFERENCES}

1. VShE podgotovila prognoz razvitiya agropromyshlenno kompleksa do 2030 goda [The Higher School of Economics Prepared a Forecast of the AIC Development until 2030]. Ofitsialnyy sayt Natsionalnogo issledovatelskogo universiteta «Vysshaya shkola ekonomiki» [The Official Site of the National Research University "Higher School of Economics"]. URL: https://www.hse.ru/news/ expertise/201397875.html.

2. Gladkova E.P. Analiz razlichnykh form partnerstva $\mathrm{v}$ sfere APK: problemy i perspektivy [Analysis of Various Forms of Partnership in the Sphere of the Agroindustrial Complex: Problems and Prospects]. Upravlenie ekonomicheskimi sistemami: elektron. nauch. zhurn. [Management of Economic Systems: Electronic Scientific Journal]. URL: http:// uecs.ru/uecs-90-82016/item/4041-2016-08-09-06-27-55.

3. Kochetkova S.A. Mekhanizmy GChP v rossiyskom APK [Mechanisms of PPP in the Russian Agroindustrial Complex]. Fundamentalnye issledovaniya: nauch. zhurn. [Fundamental Research: Scientific Journal]. URL: https://www.fundamentalresearch.ru/ru/article/view?id=40867.

4. Mnatsakanyan A.G., Genne V.V. Osobennosti vzaimodeystviya gosudarstvennykh i negosudarstvennykh finansov $v$ proektakh gosudarstvenno-chastnogo partnerstva na regionalnom urovne [Peculiarities of Interaction of State and Non-State Finances in Public-Private Partnership Projects at the Regional Level]. Izvestiya $K G T U, 2011$, no. 22, pp. 18-23.

5. Mnatsakanyan R.A. Stanovlenie i razvitie gosudarstvenno-chastnogo partnerstva [Formation and Development of Public-Private Partnership]. Baltiyskiy ekonomicheskiy zhurnal, 2015, no. 2 (14), pp. 91-98.

6. Otraslevye soyuzy Rossiyskoy Federatsii [Sectoral Unions of the Russian Federation]. Ofitsialnyy sayt Ministerstva selskogo khozyaystva Rossiyskoy Federatsii [Official Website of the Ministry of Agriculture of the Russian Federation]. URL: http:/ /mcx.ru/ministry/industry-unions/.

7. Kharin A.G., Kharin G.S. Prirodopolzovanie $i$ ekologiya s osnovami ekonomiki» [Nature Management and Ecology with the Economic Basics]. Kaliningrad, Balt. in-t ekonomiki i finansov, 2006. 130 p. 
8. Chislo fermerskikh khozyaystv [Number of Farms]. Ofitsialnyy sayt Federalnoy sluzhby gosudarstvennoy statistiki [Official Website of the Federal Service of State Statistics]. URL: http://www.gks.ru/.

\section{Information about the Authors}

Albert G. Mnatsakanyan, Doctor of Sciences (Economics), Professor, Director of the Institute of Sectoral Economics and Corporate Finance, Head of the Department of Sectoral and Corporate Finance, Kaliningrad State Technical University, Malyy Pereulok, 32, 236039 Kaliningrad, Russian Federation, mag@klgtu.ru.

Viktor A. Maliy, Postgraduate Student, Department of Sectoral and Corporate Finance, Kaliningrad State Technical University, Malyy Pereulok, 32, 236039 Kaliningrad, Russian Federation, vm@gmail.com.

\section{Информация об авторах}

Альберт Гургенович Мнацаканян, доктор экономических наук, профессор, директор института отраслевой экономики и корпоративных финансов, заведующий кафедрой отраслевых и корпоративных финансов, Калининградский государственный технический университет, Малый переулок, 32, 236039 г. Калининград, Российская Федерация, mag@klgtu.ru.

Виктор Андреевич Малий, аспирант кафедры отраслевых и корпоративных финансов, Калининградский государственный технический университет, Малый переулок, 32, 236039 г. Калининград, Российская Федерация, vm@gmail.com. 